\title{
DNA methyltransferase 3A gene polymorphism contributes to daily life stress susceptibility
}

This article was published in the following Dove Press journal:

Psychology Research and Behavior Management

\author{
Melisa I Barliana ${ }^{1,2}$ \\ Shintya N Amalya' \\ Ivan S Pradipta ${ }^{3}$ \\ Sofa D Alfian ${ }^{3}$ \\ Arif SW Kusuma ${ }^{1,2}$ \\ Tiana Milanda ${ }^{1,4}$ \\ Rizky Abdulah ${ }^{3,4}$ \\ 'Department of Biological Pharmacy, \\ Biotechnology Pharmacy Laboratory, \\ ${ }^{2}$ Pharmacy Services Development \\ Research Center, ${ }^{3}$ Department of \\ Pharmacology and Clinical Pharmacy, \\ Clinical Pharmacy Laboratory, ${ }^{4}$ Center \\ for Drug Discovery and Product \\ Development, Faculty of Pharmacy, \\ Universitas Padjadjaran, Jatinangor, \\ West Java, Indonesia
}

\begin{abstract}
Daily life stress markedly affects the response toward stressful stimuli. DNA methylation is one of the factors that regulate this response, and is a normal mechanism of somatic cell growth, but its regulatory gene variations may cause alterations in the stress response. The aim of the present study was to investigate genotypic variants of the DNA methyltransferase $3 \mathrm{~A}$ $(D N M T 3 A)$ gene in 129 healthy subjects and evaluate its association with daily life stress. Blood samples were collected, and genomic DNA was isolated. DNA was amplified using specific tetra primers for DNMT3A (C/T) rs11683424 and visualized following 2\% agarose gel electrophoresis. The association of DNMT3A genetic variants with daily life stress was analyzed using the Kessler Psychological Distress Scale (K10). We observed that the distribution of subjects with genotype CC (wild type), CT (heteromutant), and TT (homomutant) was $13.95 \%, 81.4 \%$, and $4.65 \%$, respectively. Genetic variations significantly affected the daily life stress condition ( $p=0.04$ ) in Indonesian healthy subjects, but most of the subjects with the CT phenotype were classified in a stress condition.
\end{abstract}

Keywords: daily life stressor, DNA methylation, epigenetic, Kessler Psychological Distress Scale (K10), rs11683424, DNMT3A

\section{Introduction}

The response to stressful stimuli can be regulated by environmental experiences (early and later), genetic liability, and epigenetic mechanisms. ${ }^{1,2}$ Epigenetic mechanisms regulate the expression of several genes that are involved in experience-dependent plasticity, which is a structural and functional change in the brain. ${ }^{3}$ Histone modification, non-protein coding RNA, and especially DNA methylation are epigenetic mechanisms that affect heritable gene expression or phenotype without causing a transformation in the DNA sequence or genotype. . $^{-7}$

DNA methylation is required during normal somatic cell growth, and alterations in DNA methylation following stressful conditions have been shown in several stressrelated genes. ${ }^{8,9}$ A key family of enzymes that plays a role in the addition of a methyl group to cytosine at the position 5 within cytosine-guanine dinucleotides $(\mathrm{CpG})$ in the DNA sequence is the DNA methyltransferases (DNMTs: DNMT1, DNMT3A, and DNMT3B). ${ }^{9-11}$ The function of DNMT1 is to modulate the methylation process during DNA replication, whereas DNMT3A and DNMT3B are involved in de novo methylation. ${ }^{9,11}$ Inhibition of the DNMT enzymes may cause defects in cell growth, cell death, and genome instability, which shows that DNMT enzymes play a pivotal role in basic cell functions..$^{9,12-14}$
Correspondence: Melisa I Barliana Department of Biological Pharmacy, Faculty of Pharmacy, Universitas Padjadjaran, Jl. Raya Bandung Sumedang KM. 21 , Jatinangor 45363, Indonesia Tel/Fax +62 227796200

Email melisa.barliana@unpad.ac.id 
Modification in DNA methylation affects the binding of transcription factors and RNA polymerase into the DNA. Gene expression, thus, will be influenced by the location of DNA methylation and recruitment of cofactors - usually associated with decreased transcription and increased gene expression. ${ }^{1}$ Alteration in DNA methylation has been shown in several stress-related conditions. Low expression of hippocampal glucocorticoid receptor (GR) with hypermethylation of the GR gene was shown in subjects exposed to prenatal stressor, postnatal stressor, and childhood maltreatment. ${ }^{15-19}$

DNMT3A has 23 exons, two isoforms (DNMT3A1 and DNMT3A2), and is regulated by an additional unique promoter. $^{20,21}$ Among three single-nucleotide polymorphisms (SNPs) of DNMT3A (rs11683424, rs1465764, and rs1465825), rs11683424 has been shown to be involved in emotional responses to daily life stress. The variability of $D N M T 3 A$ genes mainly exist in the intronic regions, including $D N M T 3 A$ rs11683424, which is correlated with the alternative splicing of the DNMT3A gene. ${ }^{3,22}$

Currently, studies about the correlation between DNA methylation and mental health are limited, especially in the Indonesian population. In the present study, we examined the association between epigenetic gene variants, such as SNP rs11683424 of DNMT3A (C/T), with daily life stress. A questionnaire tool determined the level of daily life stress. The Kessler Psychological Distress Scale (K10) is a 10-question tool that is used to screen for nonspecific psychological distress and is usually used in general purpose health surveys; it is highly precise and is effective at identifying mental illnesses. Furthermore, the K10 questionnaire is an easy and quick tool that only takes 2-3 minutes for self-administration or interviewer-administration. ${ }^{23}$ Results of this study may provide a method for preliminary screening that may enable the targeted prevention and early intervention of mental health in Indonesian citizens.

\section{Materials and methods Subjects}

This study was an experimental study including 129 healthy subjects in Bandung city, Indonesia, who were $>18$ years old, without a history of mental disorders, not under any antipsychotic or antidepressant drugs, and not undergoing any psychological therapy. Participant information was anonymized during the analyses. All procedures conducted in studies involving human participants were approved (No. 727/UN6.C2.1.2/KEPK/PN/2014), and in accordance with, the ethical standards of the institutional and/or national research committee (Medical Research Ethics Committee of the Medical Faculty at Universitas Padjadjaran) and with the 1964 Helsinki declaration and its later amendments or comparable ethical standards. Informed consent was obtained from all individual participants included in the study.

\section{Genotyping of DNMT3A rs I I 683424}

A variant of the DNMT3A gene was identified as rs11683424 $(\mathrm{C} / \mathrm{T})$ and described in The National Center for Biotechnology Information (http://www.ncbi.nlm.nih.gov). Samples (whole blood) were collected from all subjects and stored at $-80^{\circ} \mathrm{C}$ until used in the assay. Genomic DNA was isolated using the PureLink ${ }^{\mathrm{TM}}$ Genomic DNA Mini Kit (Thermo Fisher Scientific, Waltham, MA, USA), and PCR was undertaken using 1.1× PCR SuperMix (Thermo Fisher Scientific) with specific tetra primers to identify SNPs in the DNMT3A gene (rs11683424). The tetra primers used in this analysis are as follows: primer forward 1 (F1) 5'-CTGTGCCTACTCCAAACATCATCATT-3'; primer forward 2 (F2) 5'-AGTTCAACACCCTTTCCCTGGT-3'; reverse primer 1 (R1) 5'-CAAAAATAACATCACCCTTGAAGGAG-3'; and reverse primer 2 (R2) 5' CTCCTCTGACTTTACAACCCTGC-3' (Sigma-Aldrich Co., St Louis, MO, USA). The PCR fragment was visualized by agarose gel electrophoresis (2\%) followed by ultraviolet light at $312 \mathrm{~nm}$. Three bands were visualized: the control (724 bp), C (407 $\mathrm{bp}$ ), and T (368 bp) alleles. The genotyping of $D N M T 3 A$ gene was repeated three times for each samples.

\section{Kessler Psychological Distress Scale}

All participants filled out the Kessler Psychological Distress Scale (K10) questionnaire to determine nonspecific psychological distress. Frequencies in the K10 questionnaire were described on a 5-point Likert scale with the responses: 1) all, 2) most, 3) some, 4) little, and 5) none of the time. These responses were scored from 4 to 0 and summed for a possible score range of $0-40$. Scores $<20$ were classified as not stressed, 20-24 as mild stress, 25-29 as moderate stress, and $\geq 30$ as severe stress.

\section{Statistical analysis}

Analysis of allele frequencies in each locus were calculated by chi-square test using the Hardy-Weinberg equilibrium $(d f=1)$. Correlations between the DNMT3A genetic variants and stress conditions or among the DNMT3A genetic variants, stress condition, and gender were determined by chi-square $\left(\chi^{2}\right)$ bivariate analysis (binary and multinomial logistic regression) with odds ratios (ORs) and 95\% CI. A $p<0.05$ was considered as statistically significant. 


\section{Results}

Genotyping of DNMT3A rs I I 683424 in healthy subjects

Profiling of the $D N M T 3 A$ gene (rs11683424) was undertaken using specific tetra primers. The PCR result was visualized on a $2 \%$ agarose gel: the $\mathrm{CC}$ genotype was shown at $407 \mathrm{bp}$, $\mathrm{CT}$ at $368 \mathrm{bp}$ and $407 \mathrm{bp}$, and TT at $368 \mathrm{bp}$; the control band was present in all genotypes (Figure 1). The distribution of DNMT3A rs11683424 in healthy subjects was as follows: 18 subjects were wild-type CC homozygotes (13.95\%); 105 subjects were CT heterozygotes (81.4\%); and six subjects were TT homozygotes (4.65\%; Figure 2). The Hardy-Weinberg equilibrium showed that the frequencies of the genotypes were in a disequilibrium state with $p<0.05$ (Table 1).

\section{Stress levels in healthy subjects by the Kessler Psychological Distress Scale}

The K10 questionnaires were validated with $p<0.05$. Analyses of the stress level in 129 healthy subjects by the K10

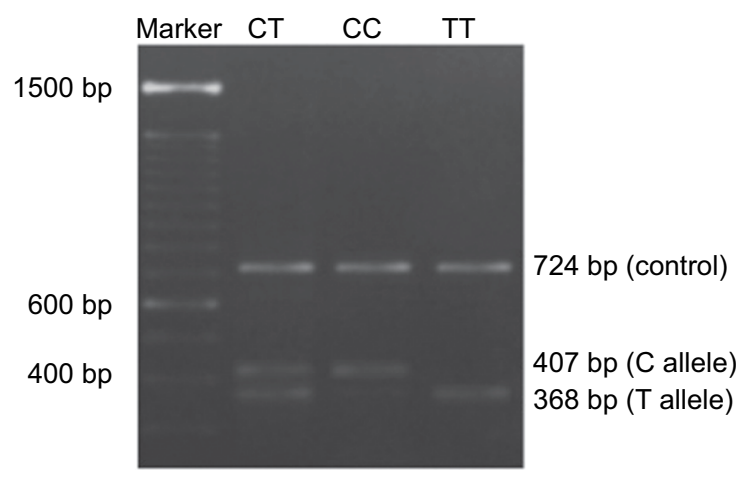

Figure I Visualization of the DNMT3A rs II683424 polymorphism using agarose gel electrophoresis.

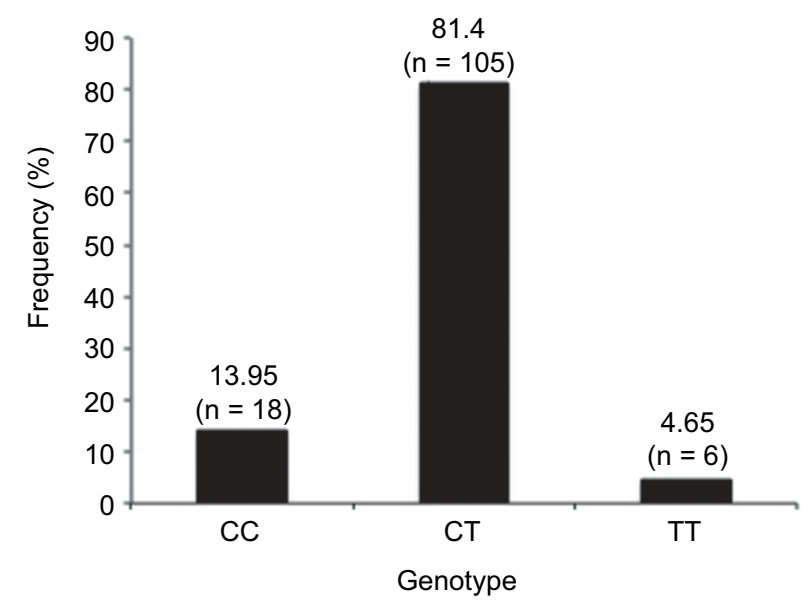

Figure 2 Frequency and variants of the DNMT3A gene (CC, CT, and TT) in healthy subjects. questionnaire showed 33 subjects with no stress (25.58\%), 48 subjects with mild stress $(37.21 \%), 33$ subjects with moderate stress $(25.58 \%)$, and 15 subjects with severe stress (11.63\%; Table 2).

\section{Correlation of stress level with the DNMT3A genotype variant}

The rs11683424 variant of DNMT3A showed multiple distributions among stress levels (K10 analysis), but the majority of subjects carried the heterozygous (CT) genotype (Figure 3). In each stress group, the CT genotype was present and accounted for $87.88 \%, 79.17 \%, 87.9 \%$, and $60 \%$ of the no, mild, moderate, and severe stress groups, respectively. Using bivariate analysis, the genotype variant significantly affected the stress level $(p=0.04)$. Within the subjects with CT genotype (Figure 3), if we compared between no stress $(n=29)$ and all stress conditions taken together (mild, moderate, and severe; $\mathrm{n}=76$ ), the incidence of stress was observed at a higher extent $(72.38 \%)$. There were no significant correlations among $D N M T 3 A$ genetic variants, stress condition, and gender. Analysis using binary logistic regression for no stress and all stress conditions (mild, moderate, and severe were grouped together as stress) resulted in a $p$-value of 0.88 , whereas multinomial logistic regression for no, mild, moderate, and severe stress resulted in a $p$-value of 0.93 (Table 3 ).

\section{Discussion}

This is the first study to study the correlations between $D N M T 3 A$ variants and the daily life stress response in healthy Indonesian subjects. Our results showed that most of the stress-condition subjects (mild, moderate, and severe), as determined with the $\mathrm{K} 10$ questionnaire, were T-allele carriers

Table I Hardy-Weinberg equilibrium for the observed and expected genotype frequencies for DNMT3A rs I I683424

\begin{tabular}{llll}
\hline Genotype & Observed & Expected & p-value \\
\hline CC & $18(13.95 \%)$ & $38.53(29.87 \%)$ & 0.00 \\
CT & $105(81.4 \%)$ & $63.94(49.57 \%)$ & \\
TT & $6(4.65 \%)$ & $26.53(20.57 \%)$ & \\
\hline
\end{tabular}

Table 2 The Kessler Psychological Distress Scale (K I0) of healthy subjects: distribution correlated with the variations of genotype

\begin{tabular}{lllll}
\hline Genotype & \multicolumn{4}{l}{ Stress level } \\
\cline { 2 - 5 } & No & Mild & Moderate & Severe \\
\hline CC & 2 & 8 & 3 & 5 \\
CT & 29 & 38 & 29 & 9 \\
TT & 2 & 2 & 1 & 1 \\
n & 33 & 48 & 33 & 15 \\
Percentage & 25.58 & 37.21 & 25.58 & 11.63 \\
\hline
\end{tabular}




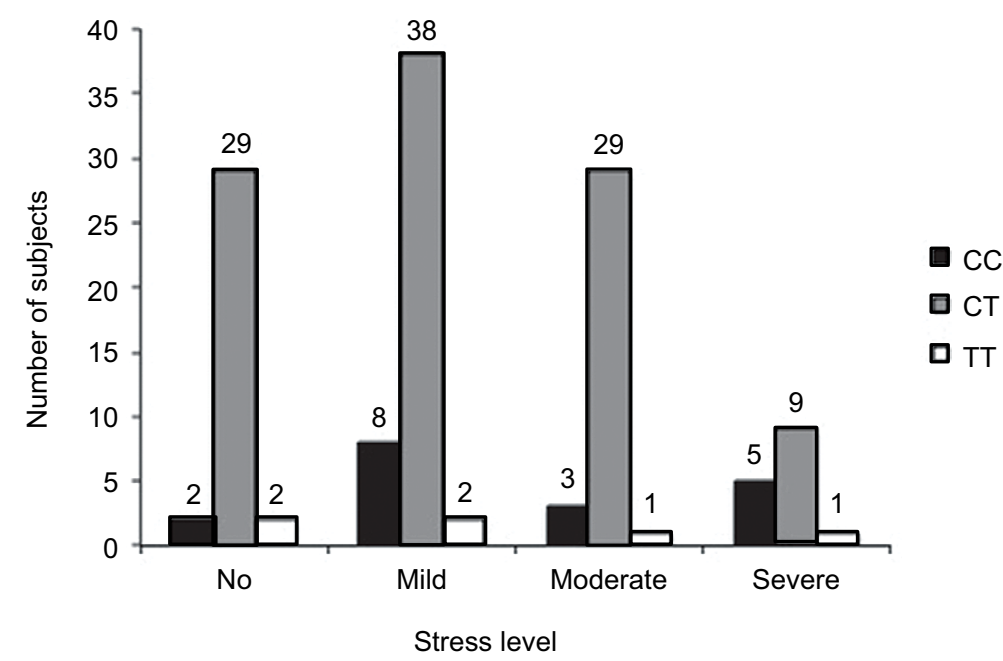

Figure 3 The Kessler Psychological Distress Scale (KI0) of healthy subjects: distribution correlated with the variation of genotype (bar graphs).

Table 3 The rs I I683424 variant of DNMT3A and gender

\begin{tabular}{|c|c|c|c|c|c|c|}
\hline \multirow[t]{2}{*}{ Stress } & \multicolumn{3}{|c|}{ Women (n) } & \multicolumn{3}{|c|}{ Men (n) } \\
\hline & $\mathrm{CC}$ & $\mathbf{C T}$ & TT & $\mathrm{CC}$ & CT & TT \\
\hline No & 2 & 21 & 2 & 0 & 8 & 0 \\
\hline Mild & 5 & 29 & I & 3 & 9 & I \\
\hline Moderate & 2 & 21 & 2 & I & 7 & 0 \\
\hline Severe & 4 & 6 & 0 & I & 3 & I \\
\hline Total (n) & 13 & 77 & 5 & 5 & 27 & 2 \\
\hline
\end{tabular}

(CT or TT) of DNMT3A rs11683424. Our results were different with the previous study in the Netherlands, which showed that the T-allele carriers of rs 11683424 were less affected by daily stress events and also that the T genotype seemed to be buffering the emotional changes. ${ }^{2}$

All subjects were in a healthy condition with no psychological disorders or use of antipsychotic therapy. The K10 questionnaire result showed that $74.42 \%$ of the respondents were in stress conditions (mild, moderate, or severe) in which only daily life stress caused their psychological condition. Although the analysis result showed that the DNMT3A genotype variant (rs11683424) significantly correlated with psychological distress ( $p=0.04)$, a specific genotype (CC, CT, or TT) was not significantly associated with distress.

There might be certain gene regulatory pathways that mediate this nonspecific psychological distress. Epigenetic alterations involved in gene regulation initiated by environmental stress occur in early infancy and regulate the hypothalamicpituitary-adrenal (HPA) pathways. ${ }^{1}$ DNA methylation of the cytosine residue is one of the epigenetic mechanisms that cause gene silencing and gene activation. ${ }^{24-26}$ Unpleasant experiences will modify DNA methylation in different stress-related genes, which may affect emotional reactivity. ${ }^{8}$
Levels of emotional reactivity to daily life stress are individual-dependent, where higher levels of emotional reactivity indicate symptoms of psychological disorder. ${ }^{27,28}$ Studies on the DNMT3A gene in the regulation of daily life stress are still limited. Other studies on the polymorphisms of DNMT3A rs11683424 have shown a significant correlation with the emotional response to daily life stress as analyzed by the Experience Sampling Methodology (ESM). ${ }^{2}$ Furthermore, variations in the DNMT3A genotype induces several diseases, such as myelodysplastic syndrome (MDS) ${ }^{29}$ and acute myeloid leukemia (AML), in southeast Asian populations. ${ }^{30,31}$ The expression of DNMT3A SNPs was increased in hepatocellular carcinoma, but it was not significantly correlated as a predictive marker. ${ }^{32}$ Another variant of $D N M T 3 A$ polymorphism at rs2289195 was observed to be associated at the genotypic level with schizophrenia in India, but was not significantly associated with onset of schizophrenia. DNMT3B rs2424932, rs1569686, and DNMT3L rs2070565 were observed to be significantly associated with early onset and familial early onset of schizophrenia in males. ${ }^{33}$

Other stress-related disorders that are affected are more prevalent in females. The RNA expression of DNMT3A in female mice after subchronic variable stress (SCVS) induction was highly stimulated. ${ }^{34}$ Epigenetic mechanisms involved in the methylation of the estrogen receptor and histone acetylation in the brain, which underline sex differences in behaviors, are vulnerable to repeated social defeat stress and mental disorders. ${ }^{35-43}$ Our results showed that there was no correlation between the rs 11683424 polymorphism of the DNMT3A gene and psychological stress. Although the CT genotype was mainly observed in females, it was distributed in all types of stress as shown by K10 analysis. 
Therefore, the gene variants were not significantly correlated with stress in females.

A similar study was done in six SNPs (rs3736963, rs2767565, rs752016, rs1327175, rs2478813, and rs716461) of plexin A2 (PLXA2) in schizophrenic subjects, and showed that the rs 2478813 variant was significantly correlated with anxiety, depression, neuroticism, and psychological distress (K10). ${ }^{44}$ Validation of the K10 questionnaire representing nonspecific psychological distress in Aboriginal people was done. Higher levels of distress were observed in females with lower education and lower household income as well as in subjects who reported poor mental health (mood disorder, anxiety disorder, and suicidal ideation). ${ }^{45}$ The K10 questionnaire is a method that is used to screen for nonspecific psychological distress as well as symptoms of depression and anxiety within 30 days. Moreover, this method was positively correlated with the Diagnostic and Statistical Manual of Mental Disorders, Fourth Edition (DSM-IV). ${ }^{23,46}$ Analysis using the K10 questionnaire is suitable for analyzing psychological distress in Indonesia, especially with regard to the many community problems that are present in a developing country. However, further clinical analysis should be included, such as blood pressure, salivary alpha amylase (SAA) and levels of cortisol, and catecholamines in blood, saliva, and urine to confirm the correlation between genetic variations with K10 questionnaire analysis.

Some studies showed that SAA and salivary cortisol level are increased in stressed condition, especially during puberty. ${ }^{47-50}$ The cortisol level in the saliva can be used as a parameter of stress condition, but the level of salivary cortisol in the morning was observed to be at a higher level than in the evening. However, physical activities, psychological condition, and type of circadian rhythm also influenced the level of salivary cortisol. ${ }^{51-53}$ Moreover, salivary alpha-amylase can be used as a biological marker for the sympathetic nervous system (SNS) to describe physiological and psychosocial stress. ${ }^{54-57}$ Differing from cortisol, levels of SAA decline an hour after awakening, increase during the rest of the day, and peak in the late afternoon or evening (diurnal profile). ${ }^{58,59}$

This study is the first report of a correlation between genotype variations with psychological distress in one particular city in Indonesia, Bandung city, as first screening and preliminary research. However, the present study provides data for the Indonesian genotype variation of $D N M T 3 A$. Although DNMT3A (rs11683424) genotypic variants were significantly correlated with psychological distress, it was not affected by gender. However, more samples are needed to describe data that represents all areas in Indonesia. For further investigation, patients with psychological disorder should be included as a comparison with healthy subjects and to confirm the involvement of $D N M T 3 A$ variations in daily life stress susceptibility. Confirmation of DNA methylation to confirm $D N M T 3 A$ gene variations should also be included using bisulfite methylation sequencing or methylationspecific PCR for further analysis.

\section{Acknowledgments}

The authors would like to thank our team: Henry Ng, Anzari Muhammad, Indah A Sagita, Casuarina Rusmawati, and Carissa P Purabaya for great team collaboration.

\section{Author contributions}

All authors contributed toward data analysis, drafting and revising the paper and agree to be accountable for all aspects of the work.

\section{Disclosure}

The authors report no conflicts of interest in this work.

\section{References}

1. Gudsnuk K, Champagne FA. Epigenetic influence of stress and the social environment. ILAR J. 2012;53(3-4):279-288.

2. Pishva E, Drukker M, Viechtbauer W, et al. Epigenetic genes and emotional reactivity to daily life events: a multi-step gene-environment interaction study. PLoS One. 2014;9(6):e100935.

3. Weaver IC, Cervoni N, Champagne FA, et al. Epigenetic programming by maternal behavior. Nat Neurosci. 2004;7(8):847-854.

4. Feinberg AP. Epigenetics at the epicenter of modern medicine. JAMA. 2008;299(11):1345-1350.

5. Meaney MJ. Epigenetics and the biological definition of gene $x$ environment interactions. Child Dev. 2010;81(1):41-79.

6. Moore LD, Le T, Fan G. DNA methylation and its basic function. Neuropsychopharmacology. 2013;38(1):23-38.

7. Weichenhan D, Plass C. The evolving epigenome. Human Mol Gen. 2013;22(R1):R1-R6.

8. Yang X, Ewald ER, Huo Y, et al. Glucocorticoid-induced loss of DNA methylation in non-neuronal cells and potential involvement of DNMT1 in epigenetic regulation of Fkbp5. Biochem Biophys Res Commun. 2012;420(3):570-575.

9. Tsumura A, Hayakawa T, Kumaki Y, et al. Maintenance of selfrenewal ability of mouse embryonic stem cells in the absence of DNA methyltransferases Dnmt1, Dnmt3a and Dnmt3b. Genes Cells. 2006;11(7):805-814.

10. Turek-Plewa J, Jagodziński PP. The role of mammalian DNA methyltransferases in the regulation of gene expression. Cell Mol Biol Lett. 2005;10(4):631-647.

11. Okano M, Bell DW, Haber DA, Li E. DNA methyltransferases Dnmt3a and Dnmt3b are essential for de novo methylation and mammalian development. Cell. 1999;99(3):247-257.

12. Xu GL, Bestor TH, Bourc'his D, et al. Chromosome instability and immunodeficiency syndrome caused by mutations in a DNA methyltransferase gene. Nature. 1999;402(6758):187-191.

13. Jackson-Grusby L, Beard C, Possemato R, et al. Loss of genomic methylation causes p53-dependent apoptosis and epigenetic deregulation. Nat Genet. 2001;27(1):31-39. 
14. Hata K, Kusumi M, Yokomine T, Li E, Sasaki H. Meiotic and epigenetic aberrations in Dnmt3L-deficient male germ cells. Mol Reprod Dev. 2006;73(1):116-122.

15. Oberlander TF, Weinberg J, Papsdorf M, Grunau R, Misri S, Devlin AM. Prenatal exposure to maternal depression, neonatal methylation of human glucocorticoid receptor gene (NR3C1) and infant cortisol stress responses. Epigenetics. 2008;3(2):97-106.

16. Murgatroyd C, Patchev AV, Wu Y, et al. Dynamic DNA methylation programs persistent adverse effects of early-life stress. Nat Neurosci. 2009;12(12):1559-1566.

17. Kember RL, Dempster EL, Lee TH, Schalkwyk LC, Mill J, Fernandes C. Maternal separation is associated with strain-specific responses to stress and epigenetic alterations to $\mathrm{Nr} 3 \mathrm{c} 1$, Avp, and $\mathrm{Nr} 4 \mathrm{a} 1$ in mouse. Brain Behav. 2012;2(4):455-467.

18. Melas PA, Wei Y, Wong CC, et al. Genetic and epigenetic associations of MAOA and $\mathrm{NR} 3 \mathrm{C} 1$ with depression and childhood adversities. Int J Neuropsychopharmacol. 2013;16(7):1513-1528.

19. McGowan PO, Sasaki A, D'Alessio AC, et al. Epigenetic regulation of the glucocorticoid receptor in human brain associates with childhood abuse. Nat Neurosci. 2009;12(3):342-348.

20. Chen T, Ueda Y, Xie S, Li E. A novel Dnmt3a isoform produced from an alternative promoter localizes to euchromatin and its expression correlates with active de novo methylation. J Biol Chem. 2002;277(41): 38746-38754.

21. Weisenberger DJ, Velicescu M, Preciado-Lopez MA, et al. Identification and characterization of alternatively spliced variants of DNA methyltransferase 3a in mammalian cells. Gene. 2002;298(1):91-99.

22. Flicek P, Amode MR, Barrell D, et al. Ensembl 2014. Nucleic Acids Res. 2014;42(Database issue):D749-D755.

23. Kessler RC, Andrews G, Colpe LJ, et al. Short screening scales to monitor population prevalences and trends in non-specific psychological distress. Psychol Med. 2002;32(6):959-976.

24. Weissman J, Naidu S, Bjornsson HT. Abnormalities of the DNA methylation mark and its machinery: an emerging cause of neurologic dysfunction. Semin Neurol. 2014;34(3):249-257.

25. Chahrour M, Jung SY, Shaw C, et al. MeCP2, a key contributor to neurological disease, activates and represses transcription. Science. 2008;320(5880):1224-1229.

26. Guo JU, Su Y, Shin JH, et al. Distribution, recognition and regulation of non-CpG methylation in the adult mammalian brain. Nat Neurosci. 2014;17(2):215-222.

27. Myin-Germeys I, van Os J, Schwartz JE, Stone AA, Delespaul PA. Emotional reactivity to daily life stress in psychosis. Arch Gen Psychiatry. 2001;58(12):1137-1144.

28. Myin-Germeys I, Peeters F, Havermans R, et al. Emotional reactivity to daily life stress in psychosis and affective disorder: an experience sampling study. Acta Psychiatr Scand. 2003;107(2):124-131.

29. Shahrabi S, Khosravi A, Shahjahani M, Rahim F, Saki N. Genetics and epigenetics of myelodysplastic syndromes and response to drug therapy: new insights. Oncol Rev. 2016;10(2):311.

30. Tan M, Ng IKS, Chen Z, et al. Clinical implications of DNMT3A mutations in a Southeast Asian cohort of acute myeloid leukaemia patients. J Clin Pathol. 2017;70(8):669-676.

31. Lin PH, Li HY, Fan SC, et al. A targeted next-generation sequencing in the molecular risk stratification of adult acute myeloid leukemia: implications for clinical practice. Cancer Med. 2017;6(2):349-360.

32. Zhao C, Yan F, Wu H, Qiao F, Qiu X, Fan H. DNMT3A -448A $>$ G polymorphism and the risk for hepatocellular carcinoma. Biomed Rep. 2013;1(4):664-668.

33. Saradalekshmi KR, Neetha NV, Sathyan S, Nair IV, Nair CM, Banerjee M. DNA methyl transferase (DNMT) gene polymorphisms could be a primary event in epigenetic susceptibility to schizophrenia. PLoS One. 2014;9(5):e98182.

34. Hodes GE, Pfau ML, Purushothaman I, et al. Sex differences in nucleus accumbens transcriptome profiles associated with susceptibility versus resilience to subchronic variable stress. J Neurosci. 2015;35(50):16362-16376.
35. Kurian JR, Olesen KM, Auger AP. Sex differences in epigenetic regulation of the estrogen receptor-alpha promoter within the developing preoptic area. Endocrinology. 2010;151(5):2297-2305.

36. Schwarz JM, Nugent BM, McCarthy MM. Developmental and hormone-induced epigenetic changes to estrogen and progesterone receptor genes in brain are dynamic across the life span. Endocrinology. 2010;151(10):4871-4881

37. Murray EK, Hien A, de Vries GJ, Forger NG. Epigenetic control of sexual differentiation of the bed nucleus of the stria terminalis. Endocrinology. 2009;150(9):4241-4247.

38. Matsuda KI, Mori H, Nugent BM, Pfaff DW, McCarthy MM, Kawata M. Histone deacetylation during brain development is essential for permanent masculinization of sexual behavior. Endocrinology. 2011;152(7):2760-2767.

39. Kim DR, Bale TL, Epperson CN. Prenatal programming of mental illness: current understanding of relationship and mechanisms. Curr Psychiatry Rep. 2015;17(2):5

40. Tsankova NM, Berton O, Renthal W, Kumar A, Neve RL, Nestler EJ. Sustained hippocampal chromatin regulation in a mouse model of depression and antidepressant action. Nat Neurosci. 2006;9(4): 519-525.

41. Elliott E, Ezra-Nevo G, Regev L, Neufeld-Cohen A, Chen A. Resilience to social stress coincides with functional DNA methylation of the Crf gene in adult mice. Nat Neurosci. 2010;13(11):1351-1353.

42. LaPlant Q, Vialou V, Covington HE 3rd, et al. Dnmt3a regulates emotional behavior and spine plasticity in the nucleus accumbens. Nat Neurosci. 2010;13(9):1137-1143.

43. Golden SA, Christoffel DJ, Heshmati M, et al. Epigenetic regulation of $\mathrm{RAC} 1$ induces synaptic remodeling in stress disorders and depression. Nat Med. 2013;19(3):337-344.

44. Wray NR, James MR, Mah SP, et al. Anxiety and comorbid measures associated with PLXNA2. Arch Gen Psychiatry. 2007;64(3): 318-326.

45. Bougie E, Arim RG, Kohen DE, Findlay LC. Validation of the 10-item Kessler Psychological Distress Scale (K10) in the 2012 Aboriginal Peoples Survey. Health Rep. 2016;27(1):3-10.

46. Kessler RC, Barker PR, Colpe LJ, et al. Screening for serious mental illness in the general population. Arch Gen Psychiatry. 2003;60(2):184-189.

47. Strahler J, Skoluda N, Kappert MB, Nater UM. Simultaneous measurement of salivary cortisol and alpha-amylase: application and recommendations. Neurosci Biobehav Rev. Epub 2017 Aug 31.

48. Ji J, Negriff S, Kim H, Susman EJ. A study of cortisol reactivity and recovery among young adolescents: heterogeneity and longitudinal stability and change. Dev Psychobiol. 2016;58(3):283-302.

49. Strahler J, Mueller A, Rosenloecher F, Kirschbaum C, Rohleder N. Salivary alpha-amylase stress reactivity across different age groups. Psychophysiology. 2010;47(3):587-595.

50. Almela M, Hidalgo V, Villada C, et al. Salivary alpha-amylase response to acute psychosocial stress: the impact of age. Biol Psychol. 2011;87(3):421-429.

51. Bonato M, La Torre A, Saresella M, Marventano I, Merati G, Vitale JA. Salivary cortisol concentration after high-intensity interval exercise: time of day and chronotype effect. Chronobiol Int. 2017;34(6): 698-707.

52. Kudielka BM, Federenko IS, Hellhammer DH, Wüst S. Morningness and eveningness: the free cortisol rise after awakening in "early birds" and "night owls". Biol Psychol. 2006;72(2):141-146.

53. Dickerson SS, Kemeny ME. Acute stressors and cortisol responses: a theoretical integration and synthesis of laboratory research. Psychol Bull. 2004;130(3):355-391.

54. Chatterton RT Jr, Vogelsong KM, Lu YC, Ellman AB, Hudgens GA. Salivary alpha-amylase as a measure of endogenous adrenergic activity. Clin Physiol. 1996;16(4):433-448.

55. Nater UM, La Marca R, Florin L, et al. Stress-induced changes in human salivary alpha-amylase activity -- associations with adrenergic activity. Psychoneuroendocrinology. 2006;31(1):49-58. 
56. Nater UM, Rohleder N, Gaab J, et al. Human salivary alpha-amylase reactivity in a psychosocial stress paradigm. Int J Psychophysiol. 2005;55(3):333-342.

57. Schumacher S, Kirschbaum C, Fydrich T, Ströhle A. Is salivary alphaamylase an indicator of autonomic nervous system dysregulations in mental disorders?--a review of preliminary findings and the interactions with cortisol. Psychoneuroendocrinology. 2013;38(6):729-743.
58. Nater UM, Rohleder N, Schlotz W, Ehlert U, Kirschbaum C. Determinants of the diurnal course of salivary alpha-amylase. Psychoneuroendocrinology. 2007;32(4):392-401.

59. Rohleder N, Nater UM, Wolf JM, Ehlert U, Kirschbaum C. Psychosocial stress-induced activation of salivary alpha-amylase: an indicator of sympathetic activity? Ann NY Acad Sci. 2004;1032:258-263.

\section{Publish your work in this journal}

Psychology Research and Behavior Management is an international, peerreviewed, open access journal focusing on the science of psychology and its application in behavior management to develop improved outcomes in the clinical, educational, sports and business arenas. Specific topics covered in the journal include: Neuroscience, memory and decision making; Behavior
Submit your manuscript here: https://www.dovepress.com/psychology-research-and-behavior-management-journal 